\title{
Midnight salivary cortisol for the diagnosis of Cushing's syndrome in a Chinese population
}

\author{
Dao-Chen $\underline{\operatorname{Lin}}^{1,2}$, MD, Pei-Shan $\underline{\operatorname{Tsai}}^{3,4,5}$, MD, Yi-Chun $\underline{\operatorname{Lin}}^{2,6}$, MD
}

INTRODUCTION Cushing's syndrome is defined as chronic excess free cortisol in circulation. According to recent studies, midnight salivary cortisol is an accurate and non-stress method for screening and diagnosing Cushing's syndrome. However, there is limited data on midnight salivary cortisol for diagnosing Cushing's syndrome in the Chinese population. METHODS Among 61 suspected Chinese patients, 48 patients were confirmed to have Cushing's syndrome. We evaluated the midnight salivary cortisol, midnight serum cortisol and 24-hour urine free cortisol excretion for diagnosis. Midnight salivary cortisol was collected from 21 healthy volunteers for control purposes.

RESULTS In the patient group, mean urine free cortisol excretion and midnight salivary cortisol levels were $296.50 \pm$ $47.99 \mu \mathrm{g} /$ day and $10.18 \pm 1.29 \mathrm{ng} / \mathrm{mL}$, respectively. Among the control group and normal participants, mean midnight salivary cortisol level was $0.53 \pm 0.13 \mathrm{ng} / \mathrm{mL}$ and $0.50 \pm 0.12 \mathrm{ng} / \mathrm{mL}$, respectively. The cut-off value for midnight salivary cortisol was $1.7 \mathrm{ng} / \mathrm{mL}$ for diagnosing Cushing's syndrome, with a sensitivity of $98 \%$ and specificity of $100 \%$. The diagnostic performance of midnight salivary cortisol (area under the curve $[A U C]=0.99$ ) was superior to that of urine free cortisol (AUC = 0.89).

CONCLUSION Our study confirmed the good diagnostic performance of midnight salivary cortisol for diagnosing Cushing's syndrome in a Chinese population. Correlation between midnight salivary cortisol and either urine free cortisol or midnight serum cortisol was good. Midnight salivary cortisol is a convenient and precise tool for diagnosing Cushing's syndrome and can be the screening test of choice for Chinese populations.

Keywords: Cushing's disease, Cushing's syndrome, midnight salivary cortisol, midnight serum cortisol, urine free cortisol

\section{INTRODUCTION}

Endogenous hypercortisolism causing Cushing's syndrome (CS) is a rare disorder, with an estimated incidence of 0.7-2.4 per million person-years. ${ }^{(1-3)}$ Its clinical features, such as hypertension, glucose intolerance, amenorrhoea, hirsutism, purple striae and central obesity, are nonspecific and tend to vary greatly. In high-risk populations, the prevalence of endogenous hypercortisolism may be higher than expected. In some studies, endogenous hypercortisolism was demonstrated in $0.5 \%-1 \%$ of patients with hypertension, ${ }^{(4,5)} 2 \%-3 \%$ of patients with poorly controlled diabetes mellitus, ${ }^{(6,7)}$ and up to $11 \%$ of all patients with osteoporosis and vertebral fractures. ${ }^{(8)}$

Therefore, the diagnosis of CS is primarily based on biochemical confirmation. Traditionally, urine free cortisol (UFC) excretion and low-dose dexamethasone suppression test (LDDST) are the most commonly used diagnostic tests to exclude or confirm its diagnosis. However, several factors may affect the test results, such as improper urine collection, drug interactions, and altered metabolism and absorption of dexamethasone. ${ }^{(9)}$ Moreover, the use of both UFC excretion and LDDST is limited in patients with renal failure. Therefore, the correct diagnosis of CS remains a challenge for endocrinologists.

Evans et al were the first to introduce the measurement of midnight salivary cortisol (MSC) level for evaluating hypercortisolism in the 1980s. ${ }^{(10)}$ Since then, MSC, a free and active form of serum cortisol, is considered to be an accurate and convenient tool for this purpose. ${ }^{(11-19)}$ In patients with suspected CS, MSC has good diagnostic sensitivity (range 92\%-100\%) and specificity (range 93\%-100\%)..$^{11-14,20-26)}$ Moreover, its concentration shows a positive correlation with the excretion of UFC.

However, the diagnostic efficacy of MSC in the Chinese population and the optimal cut-off level of MSC for diagnosis of CS have not been well investigated. In this study, we assessed the diagnostic performance of MSC and its correlation with UFC levels in 48 consecutive Chinese patients with histologically proven CS.

\section{METHODS}

The study was approved by the ethical committee at Taipei Veterans General Hospital, Taipei, Taiwan. Written informed consent was obtained from all patients according to the Helsinki Declaration, as revised in 2000.

Between January 2002 and December 2015, 61 patients suspected to have CS were admitted to our hospital for evaluation. The work-up of patients included the following investigations: (a) measurement of serum cortisol and plasma adrenocorticotropic hormone (ACTH) concentrations in the morning (between 0800 hours and 0900 hours) and at midnight (between 2300 hours and 0000 hours, as midnight serum cortisol [MseC]) for two

\footnotetext{
${ }^{1}$ Department of Radiology, ${ }^{2}$ Division of Endocrinology and Metabolism, Department of Medicine, Taipei Veterans General Hospital, ${ }^{3}$ Department of Radiology, Mackay Memorial Hospital, ${ }^{4}$ Mackay Junior College of Medicine, Nursing and Management, ${ }^{5}$ Department of Medicine, Mackay Medical College, ${ }^{6}$ Faculty of Medicine, National Yang-Ming University, Taipei, Taiwan

Correspondence: Dr Yi-Chun Lin, Division of Endocrinology and Metabolism, Department of Medicine, Taipei Veterans General Hospital, No. 201, Sec 2, Shipai Rd, Beitou District, Taipei City, 11217, Taiwan. dclin@vghtpe.gov.tw
} 
consecutive days; (b) measurement of MSC levels in saliva samples collected between 2300 hours and 0000 hours on the same two days; (c) 24-hour UFC levels on the same two days; and (d) LDDST.

For the control group, 13 patients, who were excluded from the suspected CS group based on normal diurnal cortisol circadian rhythm and suppressible LDDST, were enrolled.

The aetiology of CS was determined on the basis of imaging studies and hormone function tests. The final diagnosis included: Cushing's disease (CD; $\mathrm{n}=29$ ); adrenal CS ( $\mathrm{n}=15$ [adrenal adenoma, $\mathrm{n}=13$; adrenal carcinoma, $\mathrm{n}=1$; macronodular adrenal hyperplasia, $n=1])$; and ectopic ACTH syndrome ( $n=4$; negative for bilateral inferior petrosal sinus sampling). Except for ectopic ACTH syndrome, all patients with $\mathrm{CD}$ and adrenal CS were confirmed on histopathological examination of resected tissues - CD by trans-sphenoidal hypophysectomy and adrenal CS by adrenalectomy.

Additionally, 21 healthy individuals in the age group 20-40 years without any history and evidence of endocrine disorder or systemic disease were recruited as volunteers to serve as the normal participants (NP) group. Midnight saliva samples (between 2300 hours and 0000 hours) of these 21 volunteers were collected for two consecutive days. However, 24-hour UFC and MSeC levels were not measured for the NP group because there was no hospitalisation in this group.

Samples of saliva and 24-hour urine were collected during hospitalisation on the same two consecutive days. At least $5 \mathrm{~mL}$ of saliva was collected at midnight by spitting into a collection tube. The saliva specimens were frozen at $-20^{\circ} \mathrm{C}$, thawed, centrifuged at 1,500 $\mathrm{g}$ for 15 minutes, and the supernatant collected and stored at $-70^{\circ} \mathrm{C}$ until further processing. All samples from an individual patient were assayed simultaneously to minimise inter-assay variation.

Salivary cortisol levels were determined in triplicate via a radioimmunoassay using rabbit anticortisol serum IgG-F-1 (IgG Corporation, Nashville, TN, USA). The antiserum reacts fully with cortisol and cross-reacts $9.4 \%$ with dihydrocortisol, $5.9 \%$ with 11 -deoxycortisol, $1.7 \%$ with corticosterone, and $<1 \%$ with tetrahydrocortisol, 17-OH-progesterone, tetrahydro-11deoxycortisol, tetrahydrocortisone and progesterone.

The tracer was cortisol-3-(O-carboxymethyl)oximino-(2-[125] iodohistamine), which was obtained from Amersham Pharmacia Biotech (IM 129, Buckinghamshire, UK) or Diagnostic Products Corporation (Coat-A-Count, Cortisol; PITKCO-4, Los Angeles, CA, USA). The sensitivity of the assay was $4-10 \mathrm{pg} /$ tube and the intra- and inter-assay coefficients of variation were $5.2 \%$ and $11.4 \%$, respectively.

Serum cortisol was assayed by immunochemiluminometric assay (ICMA; ADVIA Centaur Immunoassay System, Siemens Healthcare $\mathrm{GmbH}$, Erlangen, Germany). The antiserum reacts fully with cortisol and cross-reacts $4.6 \%$ with allotetrahydrocortisol, $2.8 \%$ with corticosterone, $7.4 \%$ with cortisone, $2.4 \%$ with 6/3-hydroxycortisol, $27 \%$ with prednisolone, $20.9 \%$ with 6-methyl-prednisolone and $6.6 \%$ with prednisone. The assay has a sensitivity of $0.2 \mu \mathrm{g} / \mathrm{dL}$ and a working range of up to

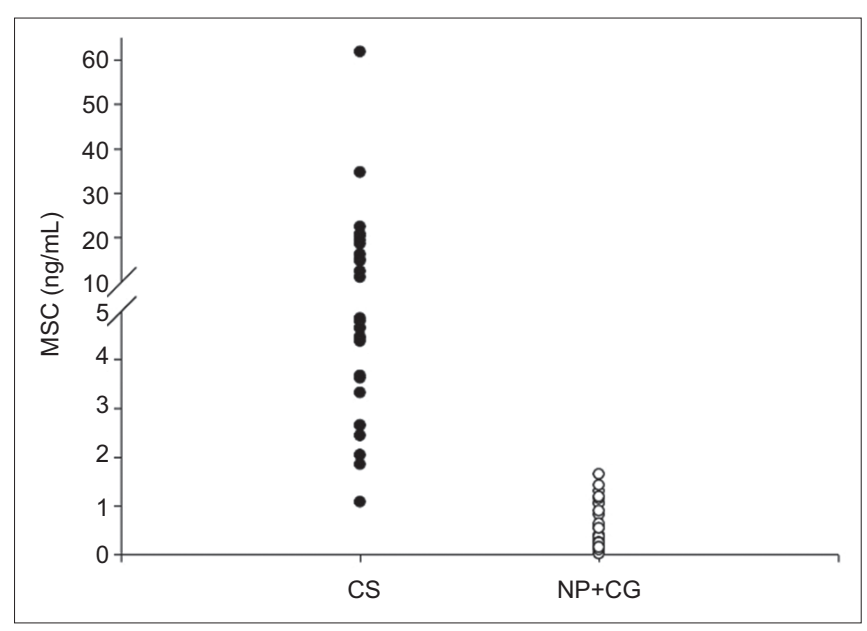

Fig. 1 Diagram shows the distribution of MSC levels among control and NP groups (open circle) and patients with CS (closed circle). CG: control group; CS: Cushing's syndrome; MSC: midnight salivary cortisol; NP: normal participants

$75 \mu \mathrm{g} / \mathrm{dL}$. The intra- and inter-assay coefficients of variation were approximately $3 \%-4 \%$.

Urine cortisol was extracted by dichloromethane, dried under a stream of nitrogen, reconstructed in assay buffer and measured using ICMA (ADVIA Centaur).

The results were presented as mean \pm standard error. Between-group differences were assessed using analysis of variance and $t$-test. Correlations were assessed by calculating the Pearson product-moment correlation coefficient. Receiver operating characteristic (ROC) curve analysis was performed to assess diagnostic performance. The cut-off value was calculated by the area under the ROC curve (AUC) with optimal sensitivity. A p-value $<0.05$ was considered to be statistically significant.

\section{RESULTS}

The clinical manifestations and results of hormone assays are summarised in Table I. Among 21 NP group participants, mean MSC level was $0.50 \pm 0.12 \mathrm{ng} / \mathrm{mL}$. For the 13 control patients, mean MSeC, MSC and 24-hour UFC levels were $3.42 \pm 0.67 \mu \mathrm{g} / \mathrm{dL}, 0.53 \pm 0.13 \mathrm{ng} / \mathrm{mL}$ and $64.85 \pm 8.99 \mu \mathrm{g} / \mathrm{day}$, respectively. No significant between-group difference in MSC level was observed between the control and NP groups.

In the CS group, mean MSeC $(18.25 \pm 1.19 \mu \mathrm{g} / \mathrm{dL})$ and 24-hour UFC (296.50 $\pm 47.99 \mu \mathrm{g} /$ day) levels were significantly higher than those in the control group $(p<0.01)$. Mean MSC level in the CS group $(10.18 \pm 1.29 \mathrm{ng} / \mathrm{mL})$ was significantly higher than that in the control and NP groups $(p<0.01)$. The distribution of MSC in patients with CS, and in the control and NP groups is shown in Fig. 1.

Among CS patients disaggregated by their different aetiologies, MSC and MSeC levels were $7.98 \pm 1.22 \mathrm{ng} / \mathrm{mL}$ and $16.72 \pm 1.28 \mu \mathrm{g} / \mathrm{dL}$ in patients with CD, $7.80 \pm 0.82 \mathrm{ng} / \mathrm{mL}$ and $16.12 \pm 0.89 \mu \mathrm{g} / \mathrm{dL}$ in patients with adrenal CS, and $32.69 \pm 10.95 \mathrm{ng} / \mathrm{mL}$ and $36.19 \pm 10.47$ $\mu \mathrm{g} / \mathrm{dL}$ in patients with ectopic ACTH syndrome. 24-hour UFC levels were $325.97 \pm 82.41 \mu \mathrm{g} /$ day, $217.36 \pm 56.76 \mu \mathrm{g} /$ day and 838.04 $\pm 178.77 \mu \mathrm{g} /$ day in patients with CD, adrenal CS and ectopic ACTH syndrome, respectively. No difference in clinical data was 
Table I. Clinical manifestations and hormone assay results of participants.

\begin{tabular}{|c|c|c|c|c|c|c|}
\hline \multirow[t]{3}{*}{ Variable } & \multicolumn{6}{|c|}{ Mean \pm SE } \\
\hline & \multicolumn{4}{|c|}{ CS aetiology } & \multirow{2}{*}{$\begin{array}{l}\text { Control group } \\
(n=13)\end{array}$} & \multirow{2}{*}{$\begin{array}{l}\text { NP group } \\
(n=21)\end{array}$} \\
\hline & $\begin{array}{l}\text { Overall } \\
(n=48)\end{array}$ & $\begin{array}{l}C D \\
(n=29)\end{array}$ & $\begin{array}{l}\text { Adrenal CS } \\
(n=15)\end{array}$ & $\begin{array}{l}\text { Ectopic ACTH } \\
\text { syndrome }(n=4)\end{array}$ & & \\
\hline \multicolumn{7}{|l|}{ Gender } \\
\hline Male & 9 & & & & 3 & 12 \\
\hline Female & 39 & & & & 10 & 9 \\
\hline Age (yr) & $43.1 \pm 2.2$ & & & & $39.9 \pm 5.5$ & $29.7 \pm 0.8$ \\
\hline BMI $\left(\mathbf{k g} / \mathbf{m}^{2}\right)$ & $27.1 \pm 0.6$ & & & & $31.1 \pm 2.6$ & $22.3 \pm 1.1$ \\
\hline $\mathrm{MSeC}(\mu \mathrm{g} / \mathrm{dL})$ & $18.25 \pm 1.19^{*}$ & $16.72 \pm 1.28$ & $16.12 \pm 0.89$ & $36.19 \pm 10.47^{\ddagger}$ & $3.42 \pm 0.67$ & NA \\
\hline MSC (ng/mL) & $10.18 \pm 1.29^{\dagger}$ & $7.98 \pm 1.22$ & $7.80 \pm 0.82$ & $32.69 \pm 10.95^{\ddagger}$ & $0.53 \pm 0.13$ & $0.50 \pm 0.12$ \\
\hline UFC ( $\mu \mathrm{g} /$ day) & $296.50 \pm 47.99^{*}$ & $325.97 \pm 82.41$ & $217.36 \pm 56.76$ & $838.04 \pm 178.77^{\ddagger}$ & $64.85 \pm 8.99$ & NA \\
\hline
\end{tabular}

${ }^{*} \mathrm{p}<0.01$ compared to control group. $\mathrm{t} p<0.01$ compared to control and NP groups. $\neq \mathrm{p}<0.05$ compared to patients with CD and adrenal CS. ACTH: adrenocorticotropic hormone; BMI: body mass index; CD: Cushing's disease; CS: Cushing's syndrome; MSC: midnight salivary cortisol; MSeC: midnight serum cortisol; NA: not available; NP: normal participants; SE: standard error; UFC: urinary free cortisol

observed between patients with CD and patients with adrenal CS. However, MSeC, MSC and 24-hour UFC levels in patients with ectopic ACTH syndrome were significantly higher than those in the other two subgroups of patients with CS $(p<0.05)$.

All CS patients had MSeC levels $>7.5 \mu \mathrm{g} / \mathrm{dL}$. The sensitivity was $100 \%$ and specificity $92 \%$. A cut-off UFC level of $80 \mu \mathrm{g} /$ day (normal range $20-80 \mu \mathrm{g} /$ day) for the diagnosis of CS was associated with $85 \%$ sensitivity and $69 \%$ specificity. A cutoff MSC level of $1.45 \mathrm{ng} / \mathrm{mL}$, (27) when used, was associated with $98 \%$ sensitivity and $100 \%$ specificity.

In the control group, a positive correlation was found between MSC and MSeC $(r=0.89 ; p<0.01)$. However, there was no significant correlation between MSC and UFC or between MSeC and UFC in this group. In patients with CS, a positive correlation was observed between MSC and UFC ( $r=0.77 ; p<0.01)$ (Fig. $2 a)$, and between MSeC and UFC ( $r=0.71 ; p<0.01$ ) (Fig. 2b). A positive correlation was also found between MSC and MSeC $(r=0.85 ; p<0.01$ ) (Fig. 2c).

On ROC curve analysis, the optimal cut-off value of MSC for the diagnosis of CS was $1.7 \mathrm{ng} / \mathrm{mL}$ (sensitivity 98\%; specificity $100 \%)$. The use of a cut-off value of $116 \mu \mathrm{g} /$ day for UFC was associated with $76 \%$ sensitivity and $100 \%$ specificity. The diagnostic performance of MSC (AUC $=0.99$ ) was superior to that of UFC (AUC $=0.89$ ) for our Chinese participants (Fig. 3).

\section{DISCUSSION}

Several recent reports indicate MSC to be an accurate and non-stress method for the screening and diagnosis of CS. ${ }^{(11-16)}$ Unlike serum cortisol, salivary cortisol is not influenced by serum binding proteins.

However, the optimal cut-off values for MSC in different studies $^{(11-14,20-26)}$ have shown wide variation (range 1.3-5.5 ng/mL), with a reported sensitivity of $92 \%-100 \%$ and specificity of $93 \%-100 \%$. This may be explained by the different assay methods used in these studies and varying characteristics of their participants. A recent meta-analysis of seven studies (total $\mathrm{n}=339$ ) revealed a sensitivity of $92 \%$ and specificity of $96 \%{ }^{(28)}$ In a study on an Asian population from Japan, ${ }^{(19)}$ an MSC threshold level $>4 \mathrm{ng} / \mathrm{mL}$ for the diagnosis of CS was associated with a sensitivity of $86 \%$ and specificity of $100 \%$.

To our knowledge, few studies have reported on the diagnosis of CS using MSC or other tests in the Chinese population. Information on the accuracy of these diagnostic tools is also lacking. In our study, a cut-off MSC level of $1.7 \mathrm{ng} / \mathrm{mL}$ was associated with a sensitivity of $98 \%$ and specificity of $100 \%$. The diagnostic performance of MSC was excellent and better than 24-hour UFC in our study $(p<0.05)$. At a cut-off level $>2.0 \mathrm{ng} / \mathrm{mL}$, the diagnostic sensitivity and specificity of MSC for our Chinese population was comparable with that reported for study populations of other ethnicities. ${ }^{(12)}$ Moreover, in the CS group, a significant positive correlation was found between MSC and either MSeC or UFC in our study. Similar results have been reported for other populations. ${ }^{(11,15,16)}$ However, among our patients without CS, the positive correlation was only found between MSC and MSeC. The reason for this, though not clear, may be related to the small sample size of our study. A further study with a larger sample size may be necessary to draw definitive conclusions about these associations.

In our study, MSC was able to distinguish patients with CS from healthy participants and those with suspected CS. Recently, MSC was recommended as the first-line screening test for CS. ${ }^{(29)}$ MSC is a simple and non-invasive test that does not require hospitalisation. Our results confirmed the accuracy and reliability of MSC as a diagnostic test for CS for the Chinese population. A normal MSC level can effectively rule out CS, except in cases with high index of suspicion for CS.

For the other diagnostic tests for CS, using the cut-off value of UFC $>116 \mu \mathrm{g}$ /day by ROC curve analysis, sensitivity was $76 \%$ and specificity was $100 \%$. The sensitivity and specificity of UFC, in our study, was comparable to those reported earlier in the other populations. ${ }^{(12)}$ Interestingly, at a cut-off level of $7.5 \mu \mathrm{g} / \mathrm{dL}$, the diagnostic performance of MSeC in our study (sensitivity $100 \%$, specificity $100 \%$ ) was superior to that of 24 -hour UFC. We also found significantly higher levels of MSeC, MSC and excretion of UFC in the subgroup of patients with ectopic ACTH syndrome 

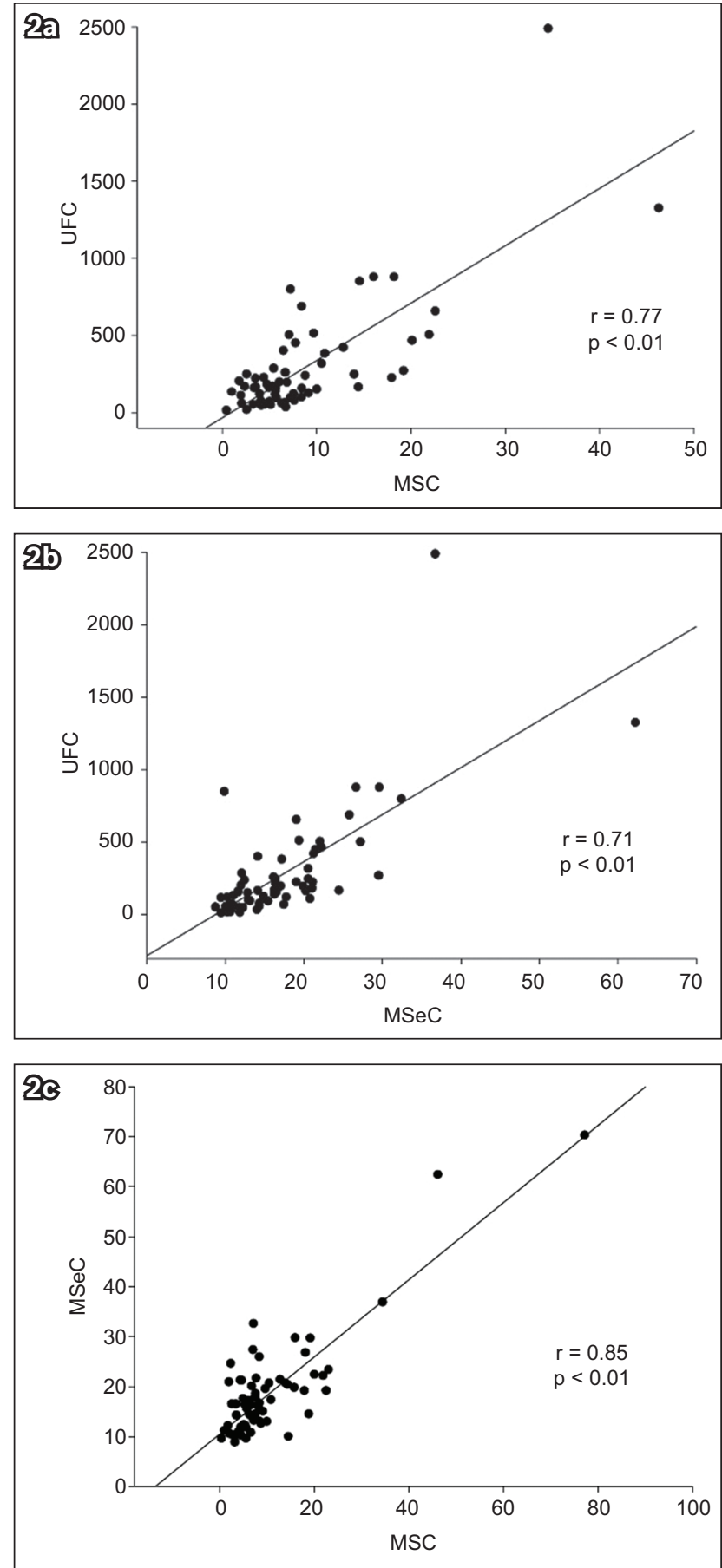

Fig. 2 (a-c) Charts show the correlations between 24-hour UFC, MSC and $\mathrm{MSeC}$ levels in patients with CS. CS: Cushing's syndrome; MSC: midnight salivary cortisol; MSeC: midnight serum cortisol; UFC: urine free cortisol

when compared to those with CD and adrenal CS. Ectopic ACTH syndrome is often associated with severe hypercortisolism and it is not unusual that significantly higher levels of MSeC, MSC and 24-hour UFC are found in patients with this CS aetiology.

In a patient with macronodular adrenal hyperplasia and impaired renal function (serum creatinine $4.0 \mathrm{mg} / \mathrm{dL}$ ), MSeC was $13.3 \mu \mathrm{g} / \mathrm{dL}$ and MSC was $6.02 \mathrm{ng} / \mathrm{mL}$. The UFC level in this patient was not consistent with CS. However, the MSC and MSeC levels confirmed a diagnosis of CS.

Some limitations of our study need to be acknowledged. First, MSC was measured by radioimmunoassay that showed cross-

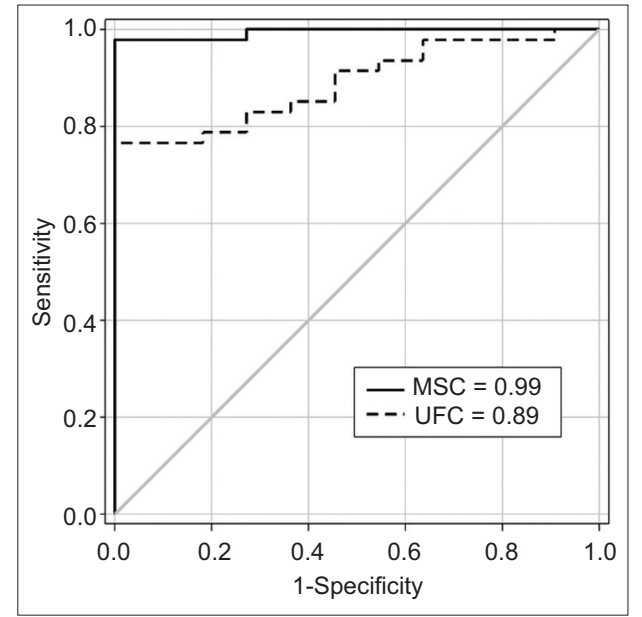

Fig. 3 Graph shows the diagnostic performance of MSC and UFC by ROC analysis. The AUCs for MSC and UFC were 0.99 and 0.89 , respectively. AUC: area under the ROC curve; MSC: midnight salivary cortisol; ROC: receiver operating characteristic curve analysis; UFC: urine free cortisol

reactivity to other steroids, including exogenous glucocorticoids or endogenous cortisol precursors and metabolites. It may falsely elevate salivary cortisol value. Second, the mean age of patients with CS was higher than that of the control and NP groups. A previous report has shown that older age was significantly associated with higher levels of salivary cortisol and this may have affected the results of MSC in our study. ${ }^{(30)}$ Third, the relatively small number of participants in the control group was a limitation. A larger sample size may be needed to verify the accuracy and reliability of the diagnostic tests identified for CS herein.

In this study, we confirmed the good diagnostic performance of MSC for Chinese patients with CS, which was comparable to that reported previously for patients of other ethnicities. MSC is an accurate, convenient and simple test for both screening and diagnostic purposes. A good correlation was observed between MSC and UFC levels in Chinese patients with CS. MSC could potentially become an alternative method for patients with renal failure for whom UFC is inaccurate. Our data showed that MSC was more accurate than UFC for the diagnosis of CS in a Chinese population, and thus MSC could be a more reliable test for its diagnosis.

\section{ACKNOWLEDGEMENTS}

We thank all participating patients and Dr Ging-Shing Won, Division of Endocrinology and Metabolism, Department of Medicine, Taipei Veterans General Hospital, Taipei City, Taiwan, for contributing to our study.

\section{REFERENCES}

1. Lindholm J, Juul S, Jørgensen JO, et al. Incidence and late prognosis of Cushing's syndrome: a population-based study. J Clin Endocrinol Metab 2001; 86:117-23.

2. Etxabe J, Vazquez JA. Morbidity and mortality in Cushing's disease: an epidemiological approach. Clin Endocrinol (Oxf) 1994; 40:479-84.

3. Ambrosi B, Bochicchio D, Ferrario R, Colombo P, Faglia G. Screening tests for Cushing's syndrome. Clin Endocrinol (Oxf) 1990; 33:809-11.

4. Anderson $\mathrm{GH}$ Jr, Blakeman N, Streeten DH. The effect of age on prevalence of secondary forms of hypertension in 4429 consecutively referred patients. J Hypertens 1994; 12:609-15.

5. Omura M, Saito J, Yamaguchi K, Kakuta Y, Nishikawa T. Prospective study on 
the prevalence of secondary hypertension among hypertensive patients visiting a general outpatient clinic in Japan. Hypertens Res 2004; 27:193-202.

6. Catargi B, Rigalleau V, Poussin A, et al. Occult Cushing's syndrome in type-2 diabetes. J Clin Endocrinol Metab 2003; 88:5808-13.

7. Leibowitz G, Tsur A, Chayen SD, et al. Pre-clinical Cushing's syndrome: an unexpected frequent cause of poor glycaemic control in obese diabetic patients. Clin Endocrinol (Oxf) 1996; 44:717-22.

8. Chiodini I, Mascia ML, Muscarella S, et al. Subclinical hypercortisolism among outpatients referred for osteoporosis. Ann Intern Med 2007; 147:541-8.

9. Putignano P, Kaltsas GA, Satta MA, Grossman AB. The effects of anti-convulsant drugs on adrenal function. Horm Metab Res 1998; 30:389-97.

10. Evans PJ, Peters JR, Dyas J, et al. Salivary cortisol levels in true and apparent hypercortisolism. Clin Endocrinol (Oxf) 1984; 20:709-15.

11. Raff $\mathrm{H}$, Raff JL, Findling JW. Late-night salivary cortisol as a screening test for Cushing's syndrome. J Clin Endocrinol Metab 1998; 83:2681-6.

12. Yaneva M, Mosnier-Pudar H, Dugué MA, et al. Midnight salivary cortisol for the initial diagnosis of Cushing's syndrome of various causes. J Clin Endocrinol Metab 2004; 89:3345-51.

13. Putignano $P$, Toja $P$, Dubini A, et al. Midnight salivary cortisol versus urinary free and midnight serum cortisol as screening tests for Cushing's syndrome. J Clin Endocrinol Metab 2003; 88:4153-7.

14. Papanicolaou DA, Mullen N, Kyrou I, Nieman LK. Nighttime salivary cortisol: a useful test for the diagnosis of Cushing's syndrome. J Clin Endocrinol Metab 2002; 87:4515-21.

15. Manetti L, Rossi G, Grasso L, et al. Usefulness of salivary cortisol in the diagnosis of hypercortisolism: comparison with serum and urinary cortisol. Eur J Endocrino 2013; 168:315-21.

16. Elias PC, Martinez EZ, Barone BF, et al. Late-night salivary cortisol has a better performance than urinary free cortisol in the diagnosis of Cushing's syndrome. J Clin Endocrinol Metab 2014; 99:2045-51.

17. Cardoso EM, Arregger AL, Tumilasci OR, Contreras LN. Diagnostic value of salivary cortisol in Cushing's syndrome (CS). Clin Endocrinol (Oxf) 2009; 70:516-21.

18. Ceccato $F$, Barbot M, Zilio M, et al. Performance of salivary cortisol in the diagnosis of Cushing's syndrome, adrenal incidentaloma, and adrenal insufficiency. Eur J Endocrinol 2013; 169:31-6.

19. Sakihara S, Kageyama K, Oki Y, et al. Evaluation of plasma, salivary, and urinary cortisol levels for diagnosis of Cushing's syndrome. Endocr J 2010; 57:331-7.

20. Luthold WW, Marcondes JA, Wajchenberg B. Salivary cortisol for the evaluation of Cushing's syndrome. Clin Chim Acta 1985; 151:33-9.

21. Castro M, Elias PC, Quidute AR, Halah FP, Moreira AC. Out-patient screening for Cushing's syndrome: the sensitivity of the combination of circadian rhythm and overnight dexamethasone suppression salivary cortisol tests. J Clin Endocrinol Metab 1999; 84:878-82.

22. Gafni RI, Papanicolaou DA, Nieman LK. Nighttime salivary cortisol measurement as a simple, noninvasive, outpatient screening test for Cushing's syndrome in children and adolescents. J Pediatr 2000; 137:30-5.

23. Laudat $\mathrm{MH}$, Cerdas S, Fournier C, et al. Salivary cortisol measurement: a practical approach to assess pituitary-adrenal function. J Clin Endocrinol Metab 1988; 66:343-8.

24. Martinelli CE Jr, Sader SL, Oliveira EB, Daneluzzi JC, Moreira AC. Salivary cortisol for screening of Cushing's syndrome in children. Clin Endocrinol (Oxf) 1999; 51:67-71.

25. Trilck M, Flitsch J, Lüdecke DK, Jung R, Petersenn S. Salivary cortisol measurement--a reliable method for diagnosis of Cushing's syndrome. Exp Clin Endocrinol Diabetes 2005; 113:225-30.

26. Viardot A, Huber P, Puder JJ, et al. Reproducibility of nighttime salivary cortisol and its use in the diagnosis of hypercortisolism compared with urinary free cortisol and overnight dexamethasone suppression test. J Clin Endocrinol Metab 2005; 90:5730-6.

27. Nieman LK, Biller BM, Findling JW, et al. The diagnosis of Cushing's syndrome: an Endocrine Society Clinical Practice Guideline. J Clin Endocrinol Metab 2008; 93:1526-40.

28. Carroll T, Raff H, Findling JW. Late-night salivary cortisol for the diagnosis of Cushing syndrome: a meta-analysis. Endocr Pract 2009; 15:335-42.

29. Raff H. Cushing's syndrome: diagnosis and surveillance using salivary cortisol. Pituitary 2012; 15:64-70.

30. Larsson CA, Gullberg B, Råstam L, Lindblad U. Salivary cortisol differs with age and sex and shows inverse associations with WHR in Swedish women: a cross-sectional study. BMC Endocr Disord 2009; 9:16. 